\title{
Rapid Situation Analysis: a hybrid, multi-methods, qualitative, participatory approach to researching tourism development phenomena
}

\author{
Christina Koutra* \\ Business School, Bournemouth University, Bournemouth, UK \\ (Received 26 June 2009; final version received 23 May 2010)
}

This study develops a hybrid, bottom-up approach to field research, namely Rapid Situation Analysis, and implements it in Ghana. It draws on elements from two existing participatory methodological approaches: Rapid Rural Appraisal and Participatory Rural Appraisal. The approach was developed to suit the particular needs of investigating corporate social responsibility practices, sustainable development and poverty reduction through tourism, a fragmented sector which tends to be ambiguous and unstructured and lack cohesion (unlike, for example, agriculture or primary health care, both of which are familiar territory for Rapid Rural Appraisal and Participatory Rural Appraisal). The Rapid Situation Analysis bottom-up approach to data gathering was underpinned by supporting methods, including participant and direct observation, in-depth interviews, stakeholder focus groups and informal conversations. Moreover, the multiple methods were further enriched by the collection of visual data in the form of moving and still images. These research findings were fed back to the communities at the centre of the research.

Keywords: participatory approaches; multiple methods; poverty; development; Africa; developing countries

\section{Introduction}

The tackling of poverty in developing countries is a social obligation for governments, multinational corporations and multinational organisations at a national, an intergovernmental and a supra-national level, especially with its institutionalisation within the Millennium Development Goals. Tourism as a sector has been actively promoted by the above-mentioned institutions as a potential catalyst for development and the fight against poverty. Tourism and, increasingly, sustainable tourism development have also been promoted in developing countries as a means for bettering people's lives. However, given local people's lack of 
involvement in tourism decision-making, one wonders whether tourism sustainability is achievable and whether this is the kind of development local people want. Perhaps they would be better off without it. Elliott (1999) argues that since it is complex in nature, there are no guarantees and no "blueprints” which assure sustainable tourism development.

However, utilising local knowledge through active local participation (Webber \& Ison, 1995) can be a step towards achieving tourism sustainability. Furthermore, Simanowitz (1997, p. 128) argues that "negative project experiences have led to the realisation that project sustainability and viability depend on community involvement" and that "the outsider knows best approach, where the external agent does the development for the recipients, created problems of factors unknown to the implementer disrupting the project objectives and undermining sustainability”. Even though real participation is difficult to achieve because it involves issues of power and control (Nelson \& Wright, 1995; Webber \& Ison, 1995), experiences from the 1980s and 1990s indicate that community participation is essential for the sustainability of a programme.

It is in this context that the Rapid Situation Analysis (RSA) - a hybrid, participatory, bottom-up research approach - was developed and used to conduct fieldwork in the towns of Elmina and Cape Coast in Ghana. This was because it allowed understanding to be derived from indigenous knowledge, as this was felt to be the most effective way to understand the views of local people (Dunn et al., 1996), especially those at the grassroots level. The specific targeting and evaluation of the on-the-ground situation allowed for amore insightful and accurate understanding of the situation in relation to sustainable tourism development. RSA enables the researcher to combine the views of local people at two stages: firstly, by involving local people - mainly those at the grassroots level - at the interview and participant observation stage and, secondly, by "feeding the data back to the community” at a later stage, which enables “indigenous knowledge” regarding, for example, hindrances to sustainability to be openly known (Dunn et al., 1996).

The latter consolidation process entails the researcher interpreting and presenting the data to the local indigenous people and allows them time for reflection, which as Webber and Ison (1995, p. 115) note "increases insight through critical reflection on experiences which makes meaning transformations possible”. This process gives indigenous people the opportunity to be informed about ongoing issues in their communities and to give feedback to the researcher 
about the data he/she has gathered. Consequently, the credibility and dependability (Denzin \& Lincoln, 1994) of data increases because the data are cross-checked, thereby increasing the probability that the outcome of the research actually represents local realities. The RSA approach was used in this study to gain insights into tourism's apparent inability to deliver sustainable development and poverty reduction at the grassroots level in the towns of Elmina and Cape Coast in Ghana, within sub-Saharan Africa. These are two poverty-stricken coastal towns where tourism was introduced in an effort to uplift the local economy and ultimately reduce poverty.

The unique characteristic of these two towns is based on the fact that they host three World Heritage Sites connected with the global slave trade: Elmina Castle (Elmina), Cape Coast Castle (Cape Coast) and Fort St Jago (Elmina). However, more than 15 years after developing tourism, this industry still has not managed to pick up. This case study context was also chosen with a view to generating knowledge that could be applied to other geographical areas with similar characteristics. These aims were addressed through the following research objectives. The first was an assessment of the relationships between the local communities, the national institutions (Ministry of Tourism, Ghana Museums and Monuments Board, Ghana Tourism Board and the local university and polytechnic), the tourism intermediaries (tour operators), external state development institutions (donor agencies) and the slave fortification castles of Elmina, St Jago and Cape Coast, thus establishing the nature of the controlling interests in the projects carried out in the locales of Cape Coast and Elmina. The second aim was to identify any corporate social responsibility practices and to assess how their presence or absence can affect sustainable tourism development at a grassroots level. And the third was an exploration of the extent to which Elmina and Cape Coast fulfil the conditions needed to become competitive destinations, thus contributing to poverty reduction. The study involved spending 5 months in the areas of Cape Coast and Elmina, comparing and contrasting the tourism systems by researching tourism stakeholders from both locales. Assessments were made of the relationships between the local communities, tourism intermediaries, national and external state development institutions and the slave fortification castles of Elmina, St Jago and Cape Coast. This facilitated an evaluation of the existing situation in the area, identifying the reasons that inhibited the sustainability of tourism and the hoped-for poverty reduction in the towns. The grounded-theory approach was used during the data collection and analysis processes. This approach generates concepts and theories inductively, since it does not contain any 
predetermined expectations (Patton, 1980). It is based on a constant comparison among the data and then with the literature. This comparison in turn enhances the credibility (Denzin \& Lincoln, 1994) and generalisability of the findings.

However, the present paper focuses mainly on the participatory approaches rather than on grounded theory per se. One reason for developing a new approach to research was because of the problems associated with the fragmented and ambiguous nature of tourism, since tourism can be a sector and an industry at the same time. Furthermore, there is debate as to whether tourism can or should be recognised as a discipline. Leiper (2000, p. 807) argues that "the debate about whether or not a discipline of Tourism Studies exists is similar to debates whether or not the industry exists”. What he means by this is that tourism is fragmented both as a topic for investigation and as an economic sector (Leiper, 2000). Hence, research approaches used to investigate tourism in its development context are, more often than not, borrowed from disciplines such as health and agriculture. Many other disciplines are employed to investigate tourism and fill the knowledge gaps created by its complexity because of the various and often-conflicting interests between consumers and producers.

\section{Developing Rapid Situation Analysis}

This study follows a qualitative, interpretive approach framed by an acknowledgement that knowledge is socially constructed (Denzin \& Lincoln, 1994) and that there can be multiple perspectives on a single subject. In this sense, unlike the positivist paradigm of a "fixed reality" that corresponds to "truth", interpretations of reality are not considered to be fixed, nor do they necessarily benefit from triangulation. Additionally, the fieldwork aimed to "understand the phenomena under study in order to develop conceptual insights rather than test a hypothesis” (Minichiello, Aroni, Timewell, \& Alexander, 1995, p. 164).

Qualitative research allows for familiarisation with the subjects and also personal reflexivity. The latter involves reflecting upon how our own values, experiences, interests, beliefs, political commitments, wider aims in life and social identities have shaped the research and how the research may have affected and possibly changed us, as people and as researchers. The use of a qualitative approach enables the views of participants to be included (EasterbySmith, Thorpe, \&Lowe, 1991; Patton, 1980). In this study it encouraged listening to the knowledge and opinions of key informants, of tourism experts and especially of local communities at the grassroots level - the marginalised, illiterate/semi-literate men, women 
and youth. Accordingly, Jennings (2001) argues that a qualitative approach to tourism has the ability to collect data that reflect social reality, including the context and attributes of the phenomenon under study. To accommodate the needs of the investigation a hybrid research approach, named Rapid Situation Analysis (RSA), was developed by combining elements of two contextually successful research approaches: Rapid Rural Appraisal (RRA) and Participatory Rural Appraisal (PRA). Additional elements were also incorporated into RSA, as will be discussed. An examination of the reasons for the development of the RSA begins with a look at the principles and uses of RRA and PRA.

\section{Rapid Rural Appraisal}

Kumar (1990) and Kumar and Casley (1993) argue that the methods of RRA come from two different intellectual traditions - phenomenology and logical positivism. Phenomenology refers to the way people or subjects experience reality, including how they react to particular social phenomenon and it seeks to comprehend the significance of those experiences. According to logical positivists, a social phenomenon is an objective social reality, in addition to existing in the minds of individuals. The fact that individuals might perceive a social phenomenon differently does not negate its existence or the application of scientific principles as a legitimate method of investigation.

At an empirical level, RRA can be described as a qualitative survey methodology (Dunn, 1993; Dunn et al., 1996). It is a systematic but semi-structured activity, carried out in agricultural settings by a small, multidisciplinary, gender-balanced team. Its aim is to elicit information and formulate new hypotheses about rural life, combining local knowledge with modern scientific expertise while eliminating any prior assumptions (Food and Agriculture Organization [FAO], 1989; Shyma \& Abraham, 1999; Townsley, 1996). RRA originated in the late 1970s in response to the theory that change would only occur if there were improvements in the living conditions of the mainly poor, rural populations of many developing countries (Chambers, 1992; Dunn, 1993).

It also developed from a general disillusionment that views about local rural tourism development were distorted because, more often than not, they were based on brief visits to rural areas by urban-based professionals (Dunn, 1994) whose experience with the rural areas and people was limited, thus affecting their perception. Additionally, it was felt there was poor understanding of the cultural and social context of development and of local 
“indigenous knowledge”. Problems directly affecting the lives (Farrington \& Martin, 1988) of key target groups, such as women and youth, were missed, while the poor were marginalised (Chambers, 1992; World Bank Group, 1994). Frequently, development initiated by multinational organisations was a top down process, meaning the real objective - to better the livelihoods of local people - was rarely accomplished because the opinions of those that mattered were never heard. By the end of the 1970s, development professionals had developed RRA, "a methodology that was rapid, cost effective and allowed outsiders to get into the knowledge of the farmers" (Moris \& Copestake, 1993, p. 39). However, professionals initially were reticent to write about and use participatory methods that were not academically acceptable (Dunn, 1994) because they were not able to produce numbers (Chambers, 1992). Many reports also failed to elucidate on their techniques or procedures (Goebel, 1998). However, by 1980 RRA had matured in terms of rigour and effectiveness and had become a focus for academic papers (Chambers, 1992).

\section{Challenges of implementing Rapid Rural Appraisal}

RRA is participatory in nature and can be economical in time, and cost-effective. It involves multidisciplinary teams with backgrounds that might include researchers, extension agents, non-governmental organisations and members of communities (Elisaba et al., 2001). It provides an integrated and coordinated approach to research with direct community involvement and empowerment in the research process while avoiding superficial investigation (Chambers, 1992; Dunn, 1994). This is accomplished by visiting less easily accessible areas and by interacting and learning from local people, including the poor - both men and women - and the more powerful and the wealthy (Elisaba et al., 2001).

It also involves conversing not only with the users of services but also with the non-users, respecting peoples' customs and traditions, travelling in the rainy and harvest seasons to view living conditions throughout the year and providing the data to the community, rather than merely extracting it for the sole use of researchers (Chambers, 1992; Dunn, 1994; Ison \& Ampt, 1992; Pido, 1995; Webber \& Ison, 1995). However, RRA is quite often implemented rapidly, which limits its validity because "it may be difficult in the short term to ensure proper integration with other disciplines so that planning can be more holistic” (Townsley, 1996, p. 2). Further, the fact that RRA is based on communication with local people makes it imperative that a person on the team speaks the local language. If interpreters are employed, they have to be trained in the techniques to avoid any bias in the interpretation procedure. 
Further, Heyer (1993) argues that translation might also miss conveying vital information which is mainly gathered during discussions. RRA is very appropriate when the description and comprehension of attitudes or motivations is required, when there is a need to interpret qualified data and when the purpose of the study is to produce suggestions or recommendations (Dunn et al., 1996; Gibbs, 1985; Pido, 1995).

However, it is inappropriate where statistical representativeness is required based on random sampling data (Heywood, 1990). RRA does not have a standard methodology, and it depends on experienced and trained researchers. If generalisation is an issue, then RRA is not an adequate substitute for careful and detailed investigation (Chambers, 1992). There is always a risk that the information obtained is not representative and is merely a compilation of specific cases, which do not reveal much about general conditions. The information may help to enhance the picture, but it does not demonstrate the scale of occurrence of a phenomenon. Heffernan (1994, p. 3) suggests that RRA only allows us "to take a glimpse" of the main problem area and that it "focuses only on the problems and misses the larger picture".

Consequently, RRA works better when incorporated into a development plan with additional institutional support (International Institute for Environment and Development, 1988). RRA takes a flexible and systematic approach. Triangulation, one of its key characteristics, enables researchers to combine various tools and techniques in order to cross-check data, integrate a diversity of disciplines and derive information from a variety of people (Dunn, 1994; Ison \& Ampt, 1992; Webber \& Ison, 1995). RRA does not follow a blueprint programme; rather it allows room for creativity and modification during the process. It is exploratory and interactive, enabling researchers to change hypotheses and related questions during the interviewing process in the light of new findings (Pido, 1995). However, it can be argued that RRA studies may come with bias and distortion and lack credibility, since researchers tend to give attention to what they want to hear.

Nevertheless, the connection with rural peoples afforded by RRA allows for the sharing of various tools, such as maps, diagrams, ranking and scoring, thereby giving researchers a more complete picture (Chambers, 1992; Conway, Husain, Alam \& Alim Mian, 1987). Ranking and scoring are especially effective for sensitive issues such as income or wealth, where people are willing to reveal relative values but would conceal or distort absolute values (Chambers, 1992; Dunn, 1994, Elisaba et al., 2001, p. 1). However, Robinson-Pant (1996) 
says that visualisation techniques seem to require western cultural practices, which in turn gives local people more knowledge of new cultural skills, and it could be argued that this misses the whole point of the investigation - learning from the existing local people's knowledge without interfering with it. In addition, introducing new means to elicit this knowledge might in the first place be off-putting for locals, and thus it might bring a bias to the outcome because it presents them with foreign concepts that they are not accustomed to, and hence it might undermine their ability to share knowledge.

Further, the iterative nature of RRA means that knowledge is reviewed in the field, and the writing stage takes place soon after the fieldwork, since any postponement might result in the loss of valuable information (Grandstaff, Grandstaff, \& Lovelace, 1987). RRA can be better understood through experience because the contact with, and the participation of, local people makes the difference (Dunn, 1993; Dunn et al., 1996; Pido, 1995). Through using RRA different viewpoints can be explored, and if well prepared, it is simple to organise and arrange (Chambers, 1992; Dunn, 1994). Optimal ignorance is of prime concern in RRA, as it requires the quantity and detail of information needed to generate the desired results within a time frame that is the minimum that is appropriate. It reminds researchers that the data gathered over an extended period must be managed by differentiating between what is and what is not worth knowing (Dunn, 1994). Appropriate imprecision is also important to RRA (Chambers, 1992), especially when there is uncertainty about the clarity of the problem.

\section{Participatory Rural Appraisal}

The term PRA was first linked to village-level investigations in Kenya in the late 1980s. Afterwards it was introduced in India and Nepal, and then it spread rapidly to many parts of the world with many applications and innovations (Chambers, 1994a). PRA promoted community participation in projects in developing countries (Webber \& Ison, 1995). It sprang from activist participatory research, work on agro-ecosystems, studies from applied anthropology, field research on farming systems (Chambers, 1994a) and RRA. PRA has advanced RRA's rapid and cost-effective methods, by helping to give outsiders access to indigenous knowledge and by allowing local people (Dunn, 1993; Dunn et al., 1996; Gona, Hartley, \& Newton, 2006; International Institute for Environment and Development, 1988) to share, analyse and enhance their knowledge of lifestyle conditions and, in the end, to plan and design development programmes (Chambers, 1992). 
PRA methods encourage local empowerment, improve rapport, tailor projects around the local situation and involve project stakeholders from various backgrounds (Pretty, Guijt, Scoones, \& Thompson, 1995; Pretty, Thompson, \& Scoones, 1999) and disciplines (Allan \& Curtis, 2002). All these features can increase the success rate (Chambers, 1994b). However, the research needed for PRA can be time-consuming. PRA is a process of communication, learning and knowledge transfer, which requires transparency through a series of open meetings (Gona et al., 2006). PRA requires teamwork between local people willing to take personal responsibility for sharing information and a multidisciplinary team with various backgrounds and experiences. A well-balanced team will represent the multiplicity of cultural, socio-economic, gender and generational perspectives (Chambers 1994a, 1994b). By these means, a reversal of roles can also be accomplished, where the local people assume an active participatory role, and the outsiders learn from them.

\section{Challenges in implementing Participatory Rural Appraisal}

PRA is a simple method not requiring visual literacy, but it can favour some techniques such as charts, which means that only fully literate groups of people can participate. Townsley (2006) indicates that research on community mapping in a tribal area of western India only represented the views of elite groups rather than the majority at the grassroots level.

Additionally, women were mostly excluded because of social constraints. However, in many cases, PRA practitioners overlook the lack of visualisation skills required. Chambers 1994a, 1994b and Eyler, Mayer, Rafil, Housemann and King (1999) argue that PRA empowers local people in decision-making processes, planning, development and research activities (Webber \& Ison, 1995), thereby facilitating the sustainability of research activities. In addition, since the information obtained becomes public knowledge, it tends to reduce cultural barriers and internal disagreements.

However, if the participants are influenced by outsiders, then barriers to communication may arise because of differences in culture and power (Lerus, 1996). There may even be a potential for failure if local planning is not an extension of the national planning and policy process. Success depends to a large extent on the attitude of the facilitator. Research in a village in western India ended before it began because local people were suspicious of the motives of the research team because of a previous experience with "outsiders" who 
disregarded the needs of the local people and used the information to accomplish their own goals.

PRA can establish links between the researchers' perceptions and those of the people upon whom innovation, change and development will ultimately depend (World Health Organization, 1988). The findings are provided directly to the community concerned (Chambers, 1994a). PRA can be cost- and time-effective and can provide a holistic perspective on the issues concerned. It enables development practitioners, governmental officials and local people to cooperate on programmes and problems in the local community (Kashyap \& Young, 1989).

Yet some institutions may not formally acknowledge research procedures and outcomes that do not comply with formal protocol (Chambers, 1994a). Heywood (1990) also states that bias might result from three different kinds of sampling errors: (1) distortions in the situations sampled for observation; (2) the timing of the observation; and (3) the selection of the people sampled. Further, PRA does not have a specific methodology and requires expertise and highly trained researchers (FAO, 1987). PRA seeks to transform the elite groups' attitudes by allowing poor people to operate in a more independent manner (Chambers, 1994a, 1994b). However, the level of local consultation and participation may raise expectations at the grassroots level (Webber \& Ison, 1995) that cannot be realised because of political or institutional contexts. The transferral of decision-making to communities can be more beneficial to certain groups than to others because they can "capture" the activity and thus monopolise its benefits (Goebel, 1998) Information obtained by PRA is indicative of the situation in the area and as such can be very helpful in formulating working hypotheses. However, if generalisation is an issue, then PRA is not an adequate substitute for detailed investigation (Chambers, 1994a, 1994b). Nevertheless, these limitations can be overcome if PRA is treated as an approach rather than a method (Allan \& Curtis, 2002) and if there is careful and methodological planning and application in both the research and implementation stages.

\section{Rapid Situation Analysis}

The design of a new approach to researching tourism development arose in part from the limitations of both RRA and PRA which handicap their application to tourism. To accommodate the study's needs a hybrid research approach was designed, which is called 
Rapid Situation Analysis (RSA). The term "rapid” means that the research is economical with the researcher's time. The term "situation” refers to the specific study locales, in this case the places where the castles are based, and the living conditions prevailing in the area. Finally, the term “analysis” refers to the researcher's attempt to identify and analyse the problem area.

\section{Principal differences between Rapid Rural Appraisal, Participatory Rural}

\section{Appraisal and Rapid Situation Analysis}

The hybrid approach was developed because some key principles of RRA and PRA could not be adhered to. The term "rural" has been completely omitted to avoid confusion. Optimal ignorance was omitted in the research because the research did not aim to gather "just enough" data to answer the research questions. On the contrary, it employed a "saturation” approach, where data collection ceased when a certain pattern of repetition occurred. Both RRA and PRA require a multidisciplinary team, while this did not apply in this present study. Additionally, taking the multi-perspective nature of the study, the work was examined according to a modified version of the Destination Competitiveness and Sustainability Model developed by Ritchie and Crouch (2003).

Additional research tools were also used in this study, such as participant observation, unstructured interviewing (with an emphasis on interviewing illiterate, semi-literate, poor and unskilled local people), video recording and photographs (thus providing some visual evidence and data for further analysis) and consultation with the University of Cape Coast. Triangulation was also omitted from this study. Instead, the multi-methods (Denzin \& Lincoln, 1994) approach was used, hence avoiding any form of "methodolatry” (Janesick, 1994) where the method always has to be justified, thus compromising the focus. The hybrid nature of the research approach allows for flexibility and adjustment according to the needs of the research.

\section{Common characteristics of Rapid Rural Appraisal, Participatory Rural Appraisal and Rapid Situation Analysis}

The research approach used in the study was participatory in nature, meaning that it sought the involvement of local people - skilled and unskilled, educated, semi-literate and illiterate, men and women. It was felt that local people know best (Dunn et al., 1996) about the area, the social structures, traditions and the living conditions and that the data gathered could reflect reality, avoiding the pitfall of typical "rural tourism development" approach biases. 
Particular emphasis was placed on the participation of illiterate, poor local people in the belief that this group owns the most exceptional and realistic knowledge concerning their living conditions and possesses ideas about what is best for them.

The nature of the study was holistic, since the aim was to deal with the complex, diverse and interdependent relationships (Dunn et al., 1996; Patton, 1980) between the local community, national and external-state institutions and the slave fortification castles of Elmina, Cape Coast and St Jago in order to identify and understand the causes that inhibit tourism development in the area. No highly structured programme was followed, thus allowing room for creativity and modification during the process. The tools used could change according to time efficiency, the resources available and the particular characteristics of the research place. The approach was also exploratory and interactive, allowing questions to be changed during the interview process in the light of new and enlightening information that better facilitated the overall aim of the project. Appropriate imprecision was also assumed, allowing for a certain level of inaccuracy, because account was taken of the fact that the researcher was an outsider "engaged in the collection of so-called objective data" (Webber \& Ison, 1995, p. 113), aiming to "understand the language and culture of the respondents" (Silverman, 2006), and because of the subjective perception of tourism development of certain individuals. Given that the direction of the study depends on local knowledge, however, the researcher also fed the data back to the local communities. The conversations were recorded, and the additional information arising was also used in the analysis process.

\section{Applying Rapid Situation Analysis in Elmina and Cape Coast}

RSA was improvised in order to ensure that there was community participation in the research process so that the results represent local realities. Therefore, observation interviewing, direct report writing and consultation with local academic institutions, as well as the process of feeding data back to the communities, ensured that the data were compared and contrasted and that the responses of the subjects were realistic.

\section{Initial contact and recruitment of a research assistant}

Upon arrival, the local academics in the School of Geography and Tourism at the University of Cape Coast were already briefed about the purpose of the visit. They very kindly assigned 
a research assistant, a prominent local figure, who assisted with the identification of the population sample, ranging from the grassroots level to the governmental level. He also assisted in translation, since the interviews with those at the grassroots level were held in the local language Fanti. However, in order to avoid any bias deriving from one persons' view of reality and thus to increase the dependability (Denzin \& Lincoln, 1994) of the data, another local university graduate was recruited. Finally, besides the research assistant, the academics themselves, along with a tourism consultant, briefed the researcher about the locality, its history, people and tourism.

\section{Observing in the field}

Given the participatory nature of the study, direct and especially participant observation was used in order to elicit as much information as possible from the local community. Observation is about exploring people's actions and behaviour (Patton, 2002) as well as examining objects, occurrences, events and interactions (Gill \& Johnson, 1991). Observation was considered essential for the research because the researcher was an outsider who "knew relatively little about the subject under investigation” (Silverman, 2006, p. 46) and it allowed the researcher to comprehend a situation more than by only using interviews (Patton, 1980).

Her presence was always associated with the "Oborunin” (white person), a characterisation she learned to accept as an honour because it commanded respect. Given the participatory character of RSA, the researcher decided to go "native” (Silverman, 2006, p. 82), living in an African village called Mepiasem, in Cape Coast, so that she could participate on a daily basis in people's social activities, such as weddings, funerals and parties. As a result, local people seemed to embrace her and make her an "insider". This also allowed for a more relaxed exchange of ideas and flow of information. This also partly increased the sense of responsibility for the researcher, as she did not want to replace objectivity, which is a major ethical issue (Webber \& Ison, 1995).

However, the researcher adopted the "being-in" approach, which involves immersing oneself in another's world, listening deeply and attentively so as to enter into the other person's experience and ensuring at the same time that she did not take a stand in support of other people by expressing her own views, perceptions, theories and biases to others (Patton, 2002; Silverman, 2006). Therefore, before commencing the interview process a month was spent wandering around the towns, watching all sorts of activities and asking questions about 
people's daily routines, gender-attributed roles and the skilled and menial occupations of men and women. Particular attention was also paid to the living conditions, infrastructure and superstructure in the area. The aim was to evaluate the poverty level of the local community and the extent to which the "tourism master plans" have assisted the poor, if at all, either by creating direct or indirect job opportunities or by improving their living conditions in relation to the infrastructure and superstructure. The main issues that emerged were assessments of the frustrations of people's daily lives and their negative and positive perceptions of the castles. These aspects were gauged through everyday conversations.

The rapid report-writing technique was considered essential because new information could emerge at any time, during informal conversations, while observing incidents or events in the field or while brainstorming the results of newly found information. Given that the questions were not predetermined (Patton, 1980), this course of action facilitated an initial evaluation of the situation and the design of a set of questions suitable for the locale's conditions. Technology (video camera and photography) was used to capture the current state of the castles, in terms of assessing the infrastructure, use for special events such as local festivals and association with any tourist activities around the castles (which mainly involved micro sellers or tours organised by tour operators in the capital). It was also used to record types of tourists, shops and current employment opportunities. These records represent changes that have occurred as a result of tourism development. To comply with ethical standards the researcher asked permission before taking photographs, and she obtained special permission from the Ghana Museum and Monuments Board to video record the castles.

\section{Identifying community people}

Given that the aim was to derive knowledge from both experts and non-experts in the tourism sector, and considering that the researcher was not a member of the communities, a purposive snowball sampling technique was used. Snowball sampling commences by asking leading local informants whom next to talk to in order to generate data that are central to the research aim (Lindolf, 1995). Attempts were made to avoid the bias that might result when a person nominates another acquaintance as an informer by consulting academics at the university, by asking the opinion of the research assistant who originates from the area and by asking about the background of the person, their experience in the tourism sector and their relevance to the research objectives. However, the theoretical sampling principles of grounded-theory data selection were also followed. This relates to "the process of data 
collecting for generating theory whereby the analyst jointly collects, codes and analyses the data and decides what data to collect next and where to find them, in order to develop his theory as it emerges” (Glaser \& Strauss, 1967, p. 45).

\section{Interviewing among the communities}

For this study, both semi-structured and unstructured interviews were employed, since both types of interview "involve an in-depth examination of people and topics" (Minichiello et al., 1995, p. 65). A set of interview questions was structured around certain topics without "fixed wording or fixed ordering of questions” (Minichiello et al., 1995, p. 65). This makes data analysis more difficult, but nonetheless it "provides a more valid explication of the informant's perception of reality” (Minichiello et al., 1995, p. 65), reveals much at "the level of emotions, the way in which they have organised their world, their thoughts about what is happening, their experiences, and their basic perceptions” (Patton, 1980, p. 28) and assists the "researcher to understand and capture the view of other people" (Patton, 1980, p. 28). The semi-structured interviews of 27 people, intended for university academics, tourism experts, and leaders/representatives, were held on a one-to-one basis, while the unstructured interview work, intended for the local communities (at the grassroots level and including men, women and young people) and polytechnic instructors, took the form of focus groups. Altogether, seven focus groups were held.

The rationale behind this division was that it enabled key comparisons to be made in order to present an unambiguous picture of tourism development in the area on the basis of comparisons between the views of those who have or do not have a stake in the tourism industry and between the views of those who compose the lower strata of society and those who compose the middle, upper middle or elitist classes in the region. This avoids the bias likely to arise from interviewing only those directly involved in the sector and/or those who come from a privileged background and might ignore poor local people, as was the case with early tourism development professionals (Dunn, 1994; Dunn et al., 1996).

Further, the division of the population into four categories enabled comparisons and contrasts to be made among the findings. The categories covered a wide range of population characteristics and geographical areas, including people from both communities as well as those who hold positions of power and live in the capital Accra. This eliminated the bias that would have been created by a lack of geographical and population diversity, and it presented 
a fuller picture of tourism development in the region. The interview questions for those at the grassroots level were simplified and translated into the local language Fanti, but the pilot study and the verification of the interview questions by three people who were all university graduates ensured that the simplified questions were not distorted. Two different sets of interviews were formulated, one for those at the grassroots level and one for the academics, key informants and tourism experts. Given the flexible, interactive and exploratory nature of RSA, the interviews allowed the exploration of other themes and nuances in order to enrich the findings. The interviewee had the chance to express his/her opinion on a specific topic, whereas the interviewer was able to listen while keeping the conversation focused on the major issues, related to “the broader aims of the project” (Silverman, 2006, p. 110).

The informal nature of semi-structured interviews was also intended to give the interviewee the elusive feeling of control over the conversation, allowing them to feel at ease and therefore making them likely to reveal more information than perhaps intended. This is the reason why semi-structured interviewing is considered one of the most efficient ways of exploring people's thoughts and feelings (Allan \& Curtis, 2002). Unstructured interviews were used to facilitate a more open conversation in which the interviewees were more relaxed, since they "take on the appearance of a normal everyday conversation" (Minichiello et al., 1995, p. 65). The flexible character of RSA allowed for the adjustment of certain questions according to literacy level, age and gender. Minimal guidance was given to the interviewees in order to avoid bias in the results. The interviewer only intervened to obtain clarification of concepts and ideas (Veal, 1997). Two categories of people were interviewed using the unstructured interviews: the polytechnic's lecturers and the local communities at the grassroots level. In the case of the local communities, the groups were selected cautiously, to eliminate the bias that could arise from including only certain groups of people. As previously mentioned, focus groups enable verification, cross-checking and collection of information about sensitive issues. The discussions were recorded on a tape recorder (permission was obtained) and handwritten notes were also kept. The recordings were transcribed immediately after the interview. The focus group discussions enabled the researcher to avoid the bias that might occur when an individual describes a phenomenon according to his/her own personal circumstances (Silverman, 2006). Focus group interviews "allow informants to react to and build upon the responses of other group members" (Steward et al., 1991, as cited in Minichiello et al., 1995, p. 8) The interview questions were simplified for those at the grassroots level because a pilot interview indicated that they could not 
comprehend complex grammatical and verbal structures. The questions were further adjusted to suit the literacy level of the interviewees because the pilot had also indicated that people at the grassroots level lacked the knowledge needed to answer particular questions, since the questions presumed knowledge of political and tourism terms.

\section{Feeding the data back to the communities}

When the data collection was completed, it was fed back to the communities through four community meetings. Dunn et al. (1996, p. 173) comment that "community meetings give the chance to local people to be listened to, share their experience, read the reports and finally take some action to do something”. The initial meeting was followed by three more because of the immense interest among local people. The meetings were again held in Fanti with a simultaneous translation into English in order to enable all participants to express their views. However, it is worth mentioning that the majority of participants could speak and understand English. At the final meeting, the community members agreed that they should continue with these meetings in the long term, and they formulated the basis for a "culture and tourism association”, which aimed to bring the requests of the stakeholders to the attention of those responsible for implementing tourism projects, not only in their community but also in the Ministry of Tourism.

\section{Findings arising from the observation work}

The participant observation work indicated that people were disillusioned by the state of tourism development in the area because it had only helped those who had financial capital to invest. Yet, at a grassroots level people welcomed tourism because they saw it as a means to an end. Even though many young men received training in artefact crafting at the castles, they remained unemployed either because they lacked capital to open their own business or because there was nobody to employ them.

Therefore, only micro-sellers benefited from tourism. As a result, it was alleged that many of these young people resorted to crime in order to survive. So tourism was welcomed more as a source of charity and social exchange rather than for its economic benefits. While several rooms in the castles were offered to people to open souvenir shops, the people who owned them were not predominantly locals. Conversations with tourists indicated that there was willingness to buy locally produced souvenirs, but the constant bargaining and the low quality put them off. Another issue was the inadequate information provided about other local 
attractions. Meetings with the towns' tour operator associations indicated that the tour operators in the area were at a disadvantage because their small size meant they could not compete with the larger tour operators from Accra. Lack of trust deterred them from cooperating with the latter.

However, there was an acknowledgement that marketing and product development is needed, but yet again lack of funding was perceived as a major obstacle. Direct observation assisted by the taking of video and still camera images indicated that the castles are in urgent need of renovation. The stairs at some points were broken, thus endangering the tourists; the dungeons were damp and smelt of mould, and there were cracks in the walls. Outside the castles, a few fruit sellers were present, as well as a few souvenir sellers; however, they targeted locals and not tourists. Direct observation also indicated that the main occupation of the locals is fishing and trading. The women predominantly trade in fish, vegetables, fruits or other household items. The men either fish or are idle. The infrastructure and superstructure in the local area is very poor; there is a sanitation problem due to open sewers, and the beaches are filthy.

\section{Findings of the local communities}

Tourism for the people at the grassroots level is associated with visiting relatives, Acquaintances and friends domestically and abroad or attending funerals. A young woman said, "[T]ourism is visiting an aunt, a sister or a friend at home or abroad, or going for a funeral”. Tourism for them is also charity taken from tourists. There is a common view that local people as a whole are neither participating in decision-making processes nor benefiting from tourism. Some old people said, “[T]he government only consults the Paramount Chief and the District Assembly for that ... [W] [Wen a project related to the castle takes place, only those who have contacts and the educated people have preference and find employment”. However, they regard community participation to be important because "the castles belong to the community, and therefore anyone who wants to do anything about and around the castle has to consult the local community. . . Unfortunately, we are excluded and because of that there is prostitution. There is unemployment”.

\section{Findings of academics, tourism experts and other key informants}

All three categories perceive that the initiatives were only successful because they brought awareness to local people. Some interviewees said, “[T] he castles before were just ghosts; the 
industry was not there. You would see occasionally a foreigner walking about, but that was it". However, the majority of the interviewees thought that "the initiative was a failure because of the strategies used; they did not invest in people, and they did not educate the people. We call these initiatives 'one-day wonders' because there are no funds to sustain them . . . Apart from the investors, I do not think that anybody benefited much. If after 15 years that tourism was introduced there are still people who have no access to running water and to a clinic and nothing is changed in the infrastructure, then you start to wonder about the benefits that tourism brought ... [S] ustainability can be achieved if there is cooperation from top to bottom, and there is not”. There were also expressions of discontent about the fact that the procedures were not transparent, so that it is not clear how much money has been given to Ghana. In addition, it was claimed that $70 \%$ of the people employed on the project were not Ghanaians, and for this reason some interviewees argued that "the money was recycled in a way back to the United States”.

The interviewees also agreed that there was no participation in decision-making or in the tourism activities by local people at the grassroots level. It is perceived that tourism is an activity that does not need planning and that it can be left to market forces and to the private sector to regulate. One interviewee said, "[L]ocal participation is very new in this country. Our planning system is top down ... [and] local people do not have a say in decision-making. However, tourism is important because it helps local people to develop. People rely only on external experts who are not in touch with the real needs of the country”. Another commented, "Even though the attraction is there and you want the tourists to stay for a minimum of 24 hours, unfortunately there are no other complimentary attractions in the area to make tourists stay longer and make the place memorable". Another said that "at the moment tourists come, see the castles, and go . . . [T]here is nothing else in the area to keep them longer . . . [T] There is no entertainment, no cultural groups; . . . cooking lessons should be made available ... [W] can carry tourists from Accra to Elmina by boats . . . Not all the guides are currently trained ... [T]hey do not have general knowledge to answer to questions regarding politics, economics, government, etc. . . Most of the tour guides at the moment are teachers who have done some history”. There is considered to be a lack of social responsibility, which is identified in the fact that no share is given back to local communities from the revenue collected from the castles. According to some interviewees, "the system needs to be decentralised, but for now everything is arranged by the government in Accra and everything goes back to Accra. So the local community cannot benefit. . . . Accra sucks up 
everything, and the local people who are supposed to benefit, they do not. We have a local proverb that is translated as follows: 'It is painful to see somebody eating in your face'. You see the food which is very well cooked, but you are not invited to take part. [The] government has taken over the royalties of the castles, and all the revenue collected goes back to the central government, and . . . not even a single percentage is given back to the local communities. Strangely enough, not even the Ministry of Tourism has a share in it. In the private sector, the people who take the lion's share are the tour operators, mainly those who operate from Accra, and that increases the resentment and indifference of local people”.

\section{Findings from feeding the data back to the communities}

The following types of findings arose from discussions with the various categories of local people: a drama/dance and radio “AHOMKA FM” group, as well as groups of "hasslers”, tailors, tour operators and leading members of the communities. Concern was expressed that tourism in the area was associated with foreigners, mainly African Americans from the diaspora, giving handouts to locals, and as a result locals learned to depend on that, and this in turn ruined the reputation of the destination. The chief fisherman, who is a leading figure in Elmina, expressed his concern that nothing will change unless people change their attitude. He said that in the past he tried to encourage people to operate more hygienically and to clean the town and to deter them from littering the streets, but people were reluctant to do so because the order did not come from the government, and people are used to following orders from the top down.

As far as the hasslers are concerned, he said that "there are a handful of people who are very notorious in the community, and that has to be stopped because they are destroying the reputation of this town". However, the hasslers stated that "hassling” the tourists is the only way they can make a living, since there are no jobs in the communities. Some of them said that they didn't beg for money, and they just tried to be clever by selling souvenirs. There was a common view that sanitation is a major issue. People defecate and dump their litter around the towns, the castles and the beaches. This is further increased by neighbouring regions that throw their litter into the rivers and the lagoon, where the current carries them all the way to Elmina. The issue of hygiene was also raised in relation to "Chop Bars" (local fast-food outlets), the lack of toilet facilities and inadequate fresh water supply which jeopardised the lives of locals and tourists. It was felt that the local food should be promoted, but its preparation and presentation should be at the highest possible standards. A request was 
also made to tour operators to encourage tourists to tour the towns and buy local products. It was pointed out that for the communities to benefit, tourists have to stay in the area for at least 2 weeks. It was often suggested that professional performances should be organised, but funding from the Tourism Board is needed. Currently, the drama/dance groups perform only at funerals and local festivals. Various trades were suggested, such as tie and dye, souvenirs and the printing of postcards. The tailors claimed that they are an asset to the towns, but yet again official funding is needed to increase their business. They were also concerned about tour guides not recommending them to tourists.

\section{Analytical overview}

The data analysis implemented through grounded theory allowed four analytical categories to emerge: social capital, human capital, financial capital and physical capital. Consequently, the inhibitors to tourism development were identified in the above four areas. In sum, the research indicated that for the locales of Elmina and Cape Coast, social responsibility is of paramount importance, since the development of tourism was held back by a lack of social responsibility towards the local population on the part of the national and external state development institutions (donor agencies) and the travel intermediaries (notably tour operators). This is mainly manifested through inadequate capacity-building in relation to the above four analytical categories. Given the Millennium Development Goals, the Ghanaian Government and donor agencies cannot ignore the importance of social responsibility if they are to meet the goal of poverty reduction in the locales of Elmina and Cape Coast.

\section{Conclusion}

The research aimed at deriving knowledge from indigenous people (Dunn et al., 1996), since it was felt that this was the most effective way to reflect the views of local people. To that end, the researcher participated directly and indirectly in people's daily lives. However, there is no participatory research approach to interpret tourism phenomena, especially to derive knowledge from indigenous people, so a hybrid, bottom-up methodological research approach was formulated, which is called Rapid Situation Analysis (RSA). The approach is partly based on elements borrowed from two other participatory approaches, namely Rapid Rural Appraisal (RRA) and Participatory Rural Appraisal (PRA) (Dunn, 1993).

The RSA approach to data gathering was underpinned by participant and direct observation, in-depth interviews, stakeholder focus groups and informal conversations. 
Moreover, the multiple methods were further enriched by the collection of visual data in the form of moving and still images. These research findings were fed back to the communities at the centre of the research. RRA is seen as a process to gather data by outsiders, while PRA is seen as a process to empower local people (Dunn, 1993; Dunn et al., 1996;Webber \& Ison, 1995). RSA did not aim to empower local people, and it did not aim to simply gather data for policymaking. It aimed to collect information in order to explain tourism developmental phenomena in the area so as to give an academic explanation regarding the hindrances to tourism development. RSA did aspire, however, to the empowerment of those who are interested in tourism, as planners, developers, entrepreneurs, consumers or hosts.

The research adopted a bottom-up approach, and accordingly emphasis was given to hearing the views of the local communities at the grassroots level (the marginalised, illiterate/semi-literate men, women and youth), since experience indicated that these people have tacit knowledge as to what could be done but do not possess the authority either to share or to utilise it. “Appropriate imprecision” was used, meaning that there is always an element of inaccuracy in all research, attributed mainly to the individuality of the researcher and that of the interviewees, since reality is very subjective and is perceived in accordance with one's experience in life. Even though the interpretivist approach was central to this research, and grounded theory was used to analyse the data, RSA allows researchers to use it in combination with any other methodological approach to suit their research needs. The grounded-theory approach was used because it is systematic, follows a standard format and induces a theory. It is an approach that is based on constant comparison among the data and that enhances the credibility, transferability, confirmability and the theoretical level of the theory. The principle of saturation was also adopted, meaning that data collection stopped when it was felt that certain themes were repeating. Of course, the interpretation of the findings has been influenced by the researcher's own beliefs, experiences and motives.

However, being an outsider was considered an advantage rather than a limitation because it enabled the researcher to be "the third eye" and without emotional attachment. This notion complies with Webber \& Ison (1995, p. 109), who contends that, dependent on the design, in participatory approaches to research the researchers can only either assume the role of the outsider or "consider themselves as part of the system under study", and this increases the objectivity of the findings. In conclusion, the application of the RSA was successful because it allowed the researcher to collect all the data needed to answer the research question. 
However, RSA should be used as a point of reference rather than as a blueprint. There are always limitations in the research that depend on the uniqueness of a destination in terms of culture, geographical location and socio-economic and political conditions. Being a bottomup approach, RSA enabled the collection of data for the majority, that is, the deprived grassroots level of the local populace. In turn, it enabled a rather close capturing of the local "spirit" and the emergence of a theory that hopefully represents reality to a great extent.

\section{Notes}

1. Intergovernmental organisations are those to which only states may belong as members, and they therefore operate above and over state boundaries. They may have multiple purposes or specialised functions, and they can be by far the most influential actors among international organisations (University of Natal, 2007).

2. Supra-national organisations are not completely intergovernmental, even though only states may belong as members, as with the intergovernmental organisation. Instead, they indicate abandonment of some aspect of sovereignty of the member states through a voluntary transfer of the decision-making power to the central body. As a result, decisions passed by a supra-national authority are binding on member states. Members must accept this authority or else withdraw from the system (University of Natal, 2007).

\section{References}

Allan, C., \& Curtis, A. (2002). Participatory Rural Appraisal. Using it to understand rural communities. Natural Resource Management, 5(1), 28-34.

Chambers, R. (1992). Rural Appraisal: Rapid, relaxed, and participatory. Discussion paper 311. Institute of Development Studies. Brighton, UK: University of Sussex.

Chambers, R. (1994a). The origins and practice of Participatory Rural Appraisal. World Development, 22(7), 953-969.

Chambers, R. (1994b). Participatory Rural Appraisal (PRA): Analysis of the experience. World Experience, 22(10), 1347-1454.

Conway, G., Husain, T., Alam, Z., \& Alim Mian, M. (1987). Rapid Rural Appraisal for sustainable development: Experiences from the northern areas of Pakistan. London: IIED.

Denzin, N.K., \& Lincoln, Y.S. (1994). Entering the field of qualitative research. In N.K. Denzin \& Y.S. Lincoln (Eds.), Handbook of qualitative research (pp. 1-17). Thousand Oaks, CA: Sage. 
Dunn, A.M. (1993). Learning to use RRA and PRA to improve the activities of two landcare groups (RRA Notes Number 18, pp. 21-32). London: International Institute for Environment and Development.

Dunn, T. (1994). Rapid Rural Appraisal: A description of the methodology and its application in teaching and research at Charles Stuart University, WaggaWagga, Australia. Rural Society, 4(4), 1-11.

Dunn, T., Humphreys, L., Muirhead, W., Plunkett, M., Croker, N., \& Nickl, M. (1996). Changing paradigms for farmer-researcher-extensionist relationships: Exploring methods and theories of farmer participation in research. European Journal of Agricultural Education and Extension, 3(3), 167-181.

Easterby-Smith, M., Thorpe, R., \& Lowe, A. (1991). Management research. London: Sage. Elliott, J. (1999). An introduction to sustainable development. (2nd ed.). London and New York: Routledge.

Elisaba, A.O., Byalebeka, J.B., Nakiganda, A., Mubiru, S., Ssenyange, D., Delve, R., Nakulenge, G. (2001). Integrated nutrient management in Iganga district, Uganda: Diagnosis by participatory learning and action research (CIAT Africa Occasional Publication Series, No. 35). CIAT, Kampala, Uganda: CIAT.

Eyler, A., Mayer, J., Rafil, R., Housemann, R., \& King, A. (1999). Key informants surveys as a tool to implement and evaluate physical activity interventions in the community. Health Education Research, 14, 289-298.

Farrington, J., \& Martin, A. (1988). Falmer participatory research: A review of concepts and recent fieldwork. Agricultural Administration and Extension, 29, 363-386.

Food and Agriculture Organization. (1987). Thematical evaluation of aquaculture. Rome: Author and Norwegian Agency for Development Cooperation.

Food and Agriculture Organization. (1989). Guidelines on communication for rural development. Rome: Author and Norwegian Agency for Development Cooperation.

Gibbs, C.J.N. (1985, September 2-5). Rapid Rural Appraisal: An overview of concepts and application. Paper presented at the International Conference on Rapid Rural Appraisal, Khon Kaen, Thailand.

Gill, J., \& Johnson, P. (1991). Research methods for managers. London: Paul Chapman.

Glaser, B.G., \& Strauss, A.L. (1967). The discovery of grounded theory: Strategies for qualitative research. Chicago, IL: Aldine.

Goebel, A. (1998). Process, perception and power: Notes from "participatory" research in a Zimbabwean resettlement area. Development and Change, 29(2), 277. 
Gona, J.K., Hartley, S., \& Newton, C.R.J. (2006). Using participatory rural appraisal (PRA) in the identification of children with disabilities in rural Kilifi Kenya. Rural and Remote Health, 6, 553. Retrieved from: http://rrh.deakin.edu.ac

Grandstaff, S.W., Grandstaff, T.B., \& Lovelace, G.W. (1987). Summary report proceedings of the 1985 International Conference on Rapid Rural Appraisal. Hon Kaen, Thailand: Hon Kaen University.

Heffernan, C. (1994). Livestock healthcare for Tibetan agropastoralists: Application of Rapid Rural Appraisal techniques. RRA Notes, 20, 54-57.

Heyer, J. (1993). Contrasts in village level fieldwork: Kenya and India. In S. Devereux \& J. Hoddinott (Eds.), Fieldwork in developing countries (pp. 29-47). Boulder, CO: Lynne Reinner. Heywood, F. (1990). W(h)ither Rapid (Rural) Appraisal techniques in nutrition. Unpublished manuscript.

International Institute for Environment and Development. (1988). RRA notes (occasional series). Sustainable agriculture programme. London: Author.

Ison, R., \& Ampt, P. (1992). Rapid Rural Appraisal: A participatory problem formulation method relevant to Australian agriculture. Agricultural Systems, 38, 247-264.

Janesick, V.J. (1994). The dance of qualitative research design: Metaphor, methodolatry and meaning. In N.K. Denzin \& Y.S. Lincoln (Eds.), A handbook of qualitative research (pp. 209-219). Thousand Oaks, CA: Sage.

Jennings, G. (2001). Tourism research. Milton, Australia: Wiley.

Kashyap, P., \& Young, R.H. (1989). Rapid assessment of community nutrition problems: A case study of Pabhani, India. Ottawa, ON, Canada: International Development Centre.

Kumar, K. (1990). An overview of rapid appraisal methods in developmental settings. Washington, DC: US Agency for International Development.

Kumar, K., \& Casley, D.J. (1993). The collection, analysis, and use of monitoring and evaluation data. Baltimore, MD: John Hopkins University Press.

Leiper, N. (2000). An emerging discipline. Annals of Tourism Research, 27(3), 805-809.

Lerus, R. (1996). Current challenges facing participatory rural appraisal. Public Administration and Development, 16, 57-72.

Lindolf, T. (1995). Qualitative communication research methods. Thousand Oaks, CA: Sage.

Minichiello, V., Aroni, R., Timewell, E., \& Alexander, L. (1995). In-depth interviewing: Principles, techniques, analysis. Melbourne, Australia: Longman. 
Moris, J., \& Copestrake, J. (1993). Qualitative enquiry for rural development. London: Intermediate Technology.

Nelson, N., \& Wright, S. (1995). Power and participatory development: Theory and practice. London: I.T.

Patton, M.Q. (1980). Qualitative evaluation methods. Beverly Hills and Newbury Park, CA: Sage.

Patton, M.Q. (2002). Qualitative research and evaluation methods. Thousand Oaks, CA: Sage.

Pido, M.D. (1995). The application of rapid rural appraisal techniques in coastal resources planning:

Experience in Malampaya Sound, Phillippines. Journal of Ocean and Coastal Management, 26(1), 57-72.

Pretty, J.N., Guijt, I., Scoones, I., \& Thompson, J. (1995). A trainers’ guide to participatory learning and action. (IIED Training Materials Series No. 1). London: IIED.

Pretty, J., Thompson, J., \& Scoones, I. (1999). Participatory learning and action: A trainers' guide. London: International Institute for Environment and Development.

Ritchie, J.R., \& Crouch, G.I. (2003). The competitive destination: A sustainable tourism perspective. Wallingford, UK: CABI.

Robinson-Pant, A. (1996). PRA: A new literacy? Journal of International Development, 8, 531-551.

Shyma, K., \& Abraham, J. (1999). Identifying disability: Comparing house to house survey and rapid rural appraisal. Health policy and planning, 14, 182-190.

Silverman, D. (2006). Interpreting qualitative data: Methods for analysing, talk, text and interaction. London: Sage.

Simanowitz, A. (1997). Water and sanitation for all: Partnerships and innovations. Community Participation/Community-Driven. 23rd WEDC Conference Durban, South Africa.

Townsley, P. (1996). Rapid rural appraisal, and participatory rural appraisal and aquaculture. Rome: Food and Agriculture Organization.

University of Natal. (2007). Politics department. Retrieved from http://www.und.ac.za/und/politics/unit3.html

Veal, A.J. (1997). Research methods for leisure and tourism. (2nd ed.). London: Financial Times/Prentice Hall. 
Webber, L., \& Ison, R.L. (1995). Participatory Rural Appraisal design: Conceptual and process issues. Agricultural Systems, 47, 107-131.

World Bank Group. (1994). Agriculture technology and services division (AGRTN) (October Agriculture Technology Notes Number 6). Washington, DC: Author.

WHO. (1988). Improving urban health: Guidelines for Rapid Rural Appraisal to assess community health needs. Geneva: WHO. 